\title{
Multiple Breath Washout
}

National Cancer Institute

\section{Source}

National Cancer Institute. Multiple Breath Washout. NCI Thesaurus. Code C130176.

A test of lung function in which changes in exhaled tracer gas concentration is analyzed for a specified number of tidal expirations, a defined period of time, or a defined index of expired gas volume. 